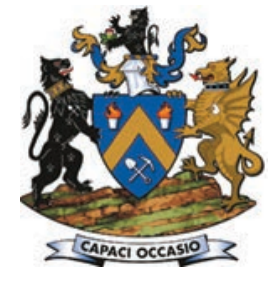

Affiliation:

1,2Department of Materials Science and Metallurgical Engineering, University of Pretoria, Pretoria, South Africa. ${ }^{3}$ Light Metals, Materials Science \& Manufacturing, CSIR, Pretoria, South Africa.

Correspondence to: M.R. Serwale

Email:

matsie.serwale@gmail.com

Dates:

Received: 16 Oct. 2019

Accepted: 21 May 2020

Published: May 2020

How to cite:

Serwale, M.R., Coetsee, T., and

Fazluddin, S

Purification of crude titanium powder produced by metallothermic reduction by acid leaching.

The Southern African Insitute of Mining and Metallurgy

DOI ID:

http://dx.doi.org/10.17159/24119717/969/2020

\section{Purification of crude titanium powder produced by metallothermic reduction by acid leaching}

\author{
M.R. Serwale ${ }^{1,2,3}$, T. Coetsee ${ }^{2}$, and S. Fazluddin ${ }^{3}$
}

\begin{abstract}
Synopsis
The CSIR is developing a process to produce commercially pure (CP) Grade 4 titanium metal powder via direct metallothermic reduction of $\mathrm{TiCl}_{4}$. Crude titanium produced by this method is inevitably contaminated with unreacted reducing metal and titanium subchlorides occluded in halide salt. For the product to meet stringent titanium industry quality requirements, the concentration of impurities must be held to acceptably low levels. Acid leaching was identified as a suitable method for purifying the crude reduction mass, due to the solubility of the by-products and the potential for cost-saving provided by this method compared to vacuum distillation. However, purification by leaching poses drawbacks such as high oxygen impurity concentrations in the product, due to the dissolution of subchlorides in water to form insoluble hydroxides and oxychlorides that concentrate on the surface of the titanium powder. The crude titanium was leached under different conditions using water and $1 \mathrm{M}$ and $0.035 \mathrm{M}$ hydrochloric acid at a temperature below $50^{\circ} \mathrm{C}$. The $1 \mathrm{M}$ acid leach yielded a product with the lowest oxygen content, demonstrating that when the $\mathrm{pH}$ of the media and temperature are controlled, the drawbacks associated with acid leaching can be overcome and the process used successfully for downstream purification of the crude product.
\end{abstract}

\section{Keywords}

titanium metal, metallothermic reduction, purification, acid leaching.

\section{Introduction}

Titanium and its alloys exhibit an exclusive combination of distinct properties such as low density, good corrosion resistance, and biocompatibility (Oosthuizen, 2011; van Vuuren, Oosthuizen and Heydenrych, 2011; Froes, 2012; Fang et al., 2018).These properties are required to produce longer life components capable of mitigating environmental problems (Hansen and Gerdemann, 1998). However, the high cost of titanium and its alloys compared to competing materials like stainless steel and aluminium limits their widespread use in the full range of potential applications (Froes and Ashraf Imam, 2010; Oosthuizen, 2011; van Vuuren, Oosthuizen, and Heydenrych, 2011; Peters et al., 2012).

Powder metallurgy (PM) techniques have been identified as a viable alternative to potentially lower titanium product costs and to ultimately spur growth (Low, Qian, and Schaffer, 2012; Fang et al., 2018). Compared to conventional fabrication methods, where up to $50 \%$ wastage is common, PM allows the use of near-net-shape technologies, which reduces scrap generation and machining (Hansen and Gerdemann, 1998; Bolzoni, Ruiz-Navas, and Gordo, 2013). In addition, the fine grain size possible with this method enhances mechanical properties and makes it possible to engineer unique alloy combinations that may not be possible with conventional ingot metallurgy (Fang et al., 2018). Despite these advantages, titanium PM is currently limited to niche applications due to the unavailability of lowcost quality powder (Froes and Ashraf Imam, 2010; Peters et al., 2012).

Commercially available powders are much more expensive than titanium sponge and other metal powders because they rely on titanium sponge as starting material (McCracken and Collin, , 2010; van Vuuren, Oosthuizen, and Heydenrych, 2011; Bolzoni, Ruiz-Navas, and Gordo, 2013; Oosthuizen and Swanepoel, 2018). The sponge is produced by metallothermic reduction of titanium tetrachloride $\left(\mathrm{TiCl}_{4}\right)$ with either magnesium (Kroll process) (Hockaday and Bisaka, 2010; Liang et al., 2018) or sodium (Hunter process) (Poulsen and Hall, 1983). Titanium sponge has the disadvantage that it is ductile and cannot be easily ground to form powder for PM applications, but instead has to either be first embrittled to form titanium hydride by heating in hydrogen, then crushed and converted into powder (Sun et al., 2017; Liang et al., 2018), a method used in the multistep hydride-dehydride (HDH) process, or be melt-refined and wrought-processed into mill forms, then reprocessed into powder, a process route used to produce gas atomized (GA) and plasma rotating electrode process (PREP) powders (Sun et al., 2017; Fang et al., 2018). For these reasons, researchers have been attempting to replace current commercial powder production methods with a process that can produce good quality titanium powder directly 


\section{Purification of crude titanium powder produced by metallothermic reduction by acid leaching}

from $\mathrm{TiCl}_{4}$ without melt purification at a cost comparable to that of impure sponge (van Vuuren, Oosthuizen, and Heydenrych, 2011).

\section{CSIR Ti process}

The CSIR is developing a process to produce 'non-melt' commercially pure (CP) titanium metal powder directly by metallothermic reduction of $\mathrm{TiCl}_{4}$ with an alkali/alkali earth metal (van Vuuren, Oosthuizen, and Heydenrych, 2011; van Vuuren and Oosthuizen, 2012; Oosthuizen and Swanepoel, 2018). This technique could increase the economic viability of titanium powder, given the potential to eliminate most of the processing steps involved in conventional wrought and powder titanium metallurgy, as illustrated in Figure 1.

Compared to titanium sponge, 'meltless' titanium powder has the advantage that components can be fabricated directly using PM techniques (Froes, 2012). By just considering the production process steps, the CSIR Ti process has the potential to be a breakthrough in cost reduction for CP grade pre-alloyed powder production. However, for the CSIR primary powder to make significant inroads in the titanium PM industry it has to meet the stringent quality requirements, which in titanium PM involve two main aspects, namely chemical composition and morphology (Sun et al., 2017). For the purpose of this study greater emphasis will be placed on chemical composition, more specifically oxygen because it is non-volatile and once in the product cannot be easily removed either chemically or by melting in vacuum (Yan, Tang, and Qian, 2015; Sun et al., 2017), and must be maintained at a minimum as its presence deteriorates the mechanical properties of titanium finished products (Wartman, 1948; Froes and Ashraf Imam, 2010; Yan, Tang, and Qian, 2015). For these reasons CP titanium is rated by its oxygen content in the form of grades (Sun et al., 2017), as illustrated in the standard (Table I).

\section{Background}

\section{Basis of the current work}

The CSIR Ti powder is produced by metallothermic reduction of $\mathrm{TiCl}_{4}$. Reduction is believed to proceed stepwise with intermediate species in the order: $\mathrm{TiCl}_{4} \rightarrow \mathrm{TiCl}_{3} \rightarrow \mathrm{TiCl}_{2} \rightarrow \mathrm{Ti}$ (Poulsen and Hall, 1983; Liang et al., 2018). Crude titanium produced by this method comprises a heterogeneous reaction mass consisting of titanium and its subchlorides, with excess alkali/alkali earth metal encapsulated in halide salt (McKinley and Avondale, 1955; Aleksandrovskii et al., 1982; Gambogi andGerdemann, 2001; Liang et al., 2018). Depending on whether the metallothermic reduction process is completed with a stoichiometric excess of the reducing metal or $\mathrm{TiCl}_{4}$, the quantities of by-products in the crude product are expected to be similar to those for the Hunter or Kroll processes, as illustrated in Table II.

Kelly (1963) acknowledged that in practice it is impossible to obtain the by-products in the crude product at the levels postulated in Table II, due to the difficulty associated with obtaining steady-state conditions - a consequence of the fast reaction rates. This was reiterated by Liang et al. (2018), who reported recoveries of subchlorides during vacuum distillation of magnesium-reduced sponge. For titanium powder to be useful downstream and to meet product specifications, it has to be separated from the reaction by-products.

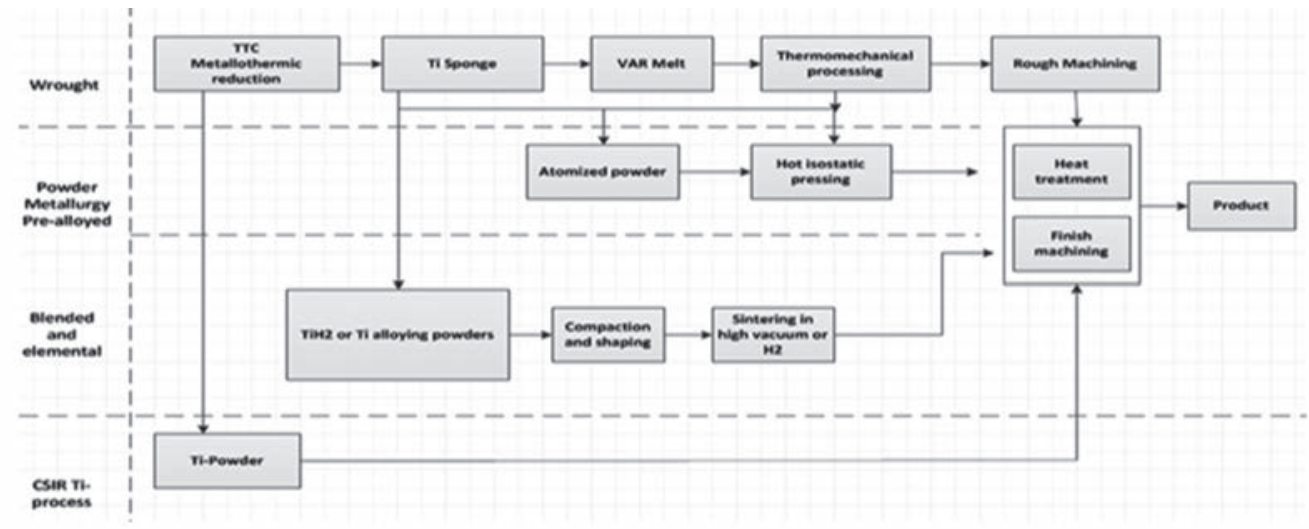

Figure 1-Block diagram summarizing the current titanium metal production process steps, including the CSIR process (adapted from Fang et al. (2018)

Table I

Chemical composition of commercial titanium powders by mass \% (Goso and Kale, 2011)

\begin{tabular}{|l|c|c|c|c|}
\hline Type & $\mathbf{O}$ & $\mathbf{N}$ & Fe \\
\hline Commercially pure grades 1-4 & $0.18-0.4$ & $0.03-0.05$ & $0.20-0.5$ & Industrial applications \\
\hline
\end{tabular}

Table II

Typical composition of the crude products from metallothermic reduction (Garmata et al., 1970; Aleksandrovskii et al., 1982)

\begin{tabular}{|l|c|c|c|}
\hline Process & Excess reducing metal (\%) & Ti subchlorides (\%) & Alkali/alkali earth metal salt (\%) \\
\hline Hunter & 0 & $0.1-4$ & $70-80$ \\
Kroll & $34-35$ & 0 & $9-10$ \\
\hline
\end{tabular}




\section{Purification of crude titanium powder produced by metallothermic reduction by acid leaching}

The removal of impurities is a significant technical challenge in titanium production as the residual by-products have direct implications for the chemical composition of the final product (Low, Qian, and Schaffer, 2012; Yan, Tang, and Qian, 2015; Liang et al., 2018). For instance, the alkali/alkali earth metal salt is hygroscopic and incomplete removal may lead to the salt absorbing water and accumulating water of hydration (van Vuuren, Oosthuizen, and Heydenrych, 2011), while titanium subchlorides in the product may react with the water of hydration to form titanium oxychlorides/hydroxides which promote an increase in oxygen content in the powder, thus degrading quality. Alkali salt and subchlorides are sources of chlorine and as such also contribute to the high content of total chlorides in the salt (Nechaev and Polezhaev, 2016)

\section{Purification methods}

Impurities can be removed by either vacuum distillation or acid leaching (Poulsen and Hall, 1983; Gambogi and Gerdemann, 2001). The selection of a suitable purification process to obtain pure titanium powder involves intricate trade-offs such as taking into account whether the selected finishing operation is cost-effective, salt downstream processing requirements, ease of recycling the brine at the required concentration suitable for re-use upstream, ease of operation, product yield efficiency, and product quality (van Vuuren, 2009). The fundamental difference between vacuum distillation and acid leaching is that the latter removes impurities by dissolving soluble constituents, and the former by evaporating the volatiles (McKinley and Avondale, 1955).

The drawback with vacuum distillation is that the process is slow and energy-intensive (Gambogi and Gerdemann, 2001; Liang et al., 2018). Hansen and Gerdemann (1998), in their efforts to produce titanium powder by continuous vapour phase reduction, found that powder purified by vacuum distillation tends to contain low oxygen levels but unacceptably high levels of chlorides due to the sintering of titanium at high temperatures resulting in powders with chloride inclusions. Acid leaching has the advantage that it consumes less energy, uses simple equipment, and large quantities of salt can be removed, resulting in reduced operating costs (Garmata et al., 2001). However, purification by leaching has drawbacks such as high oxygen and chloride impurities in the final product. This is a consequence of subchlorides dissolving in water and alkaline solutions to form insoluble hydroxides and oxychlorides, which concentrate on the surface of the titanium powder, and oxidation of titanium by water at elevated temperatures (Garmata et al., 1998). Considerable difficulties are also encountered in leaching, due to the large amounts of heat of dissolution released by the excess reducing metal, for example, $460 \mathrm{KJ} / \mathrm{g}$-atom of $\mathrm{Mg}$ and $237 \mathrm{KJ} / \mathrm{g}$ atom of $\mathrm{Na}$ (Garmata et al., 1970). It was discovered that with large excesses of reducing metal and small solution volumes, the solution is heated to boiling, which results in vigorous oxidation of the titanium and rapid precipitation of the hydroxides (Wartman, 1948). The heat of dissolution released by titanium subchlorides is not so high as to warrant cooling (Garmata et al., 1970)

Acid leaching was identified as the most suitable purification method, as it supports the CSIR's objective of a cost-effective production route. The decision was motivated by the high solubility of the alkali metal halide salt in water compared to that of magnesium chloride and sodium chloride, the straightforward nature of recovering the anhydrous metal chloride from the aqueous solutions, in addition to the other advantages discussed above (van Vuuren, 2009). The aim of these initial experiments was to demonstrate that acid leaching can be used effectively to purify crude titanium powder from the CSIR process to produce a CP Grade 4 product as a minimum, and to also develop process knowledge. The preliminary results should be seen in that light

\section{Methodology}

\section{Experimental}

Crude titanium samples used in this study were from a particular batch production run that was conducted at the CSIR with raw materials that included $\mathrm{TiCl}_{4}(99.9 \%$ by mass) and alkali/alkali earth metal ( $99.8 \%$ by mass minimum, both from Sigma Aldrich, as well as hydrochloric acid ( $32 \%$ by mass minimum) from Protea Chemicals. The reduction step was completed with a slight stoichiometric excess of $\mathrm{TiCl}_{4}$, thus it was postulated that the byproducts in the product were in proportions similar to those in processes that were completed with excess reducing metal (Table II).

\section{Procedure}

Leaching experiments were conducted using a 2-litre polypropylene beaker fitted with a Velp Scientifica ES variable speed overhead stirrer with a blade-type impeller. The samples were leached following two approaches, namely acid leaching and plain water leaching, as indicated in Table III. A volume of water was added to a beaker, the initial temperature and $\mathrm{pH}$ recorded, and then agitated. The feed was charged slowly to minimize localized heating. After charging the feed, the temperature was measured with a thermometer and recorded at 5-minute intervals for the first 15 minutes, and then at 30-minute intervals. The $\mathrm{pH}$ was monitored and recorded simultaneously. The leaching progress was followed by decantation of the pregnant leach liquor and water washing, until the powder was virtually acid-free and the conductivity of the solution close to that of pure water. The solid residue was dried at $60^{\circ} \mathrm{C}$ for 12 hours in a vacuum oven.

The experimental procedures for leaching at the two different acid concentrations were similar, the difference being that the samples were leached with hydrochloric acid solution in the first three cycles or until there were no bubbles in the leachate, and the leaching procedure was completed by washing the sample with water to dissolve all the alkali salt. The residue was subjected to the same drying conditions. The samples were analysed for oxygen and nitrogen with an ELTRA 900 $\mathrm{O}-\mathrm{N}$ analyser, and the microstructure and crystallinity were determined by scanning electron microscopy (SEM, using a JOEL EDS system), Further chemical analysis was conducted using inductively coupled plasma-optical emission spectrometry (ICP$\mathrm{OES}$ ) and X-ray diffraction (XRD - Bruker, D8 Advance) with $\mathrm{Cu}-\mathrm{K} \alpha$ radiation).

\section{Results and discussion}

\section{Effect of leaching medium on the leaching system and product quality}

The product leached in pure water had a remarkably high oxygen content compared to the acid-leached samples, as illustrated in Figure 2 .

The substantial oxygen content is attributed to the presence of excess reducing metal and titanium subchlorides reacting with water in a standard oxidation-reduction reaction to produce insoluble oxychlorides and hydroxides as per Equations [1-3]. 


\section{Purification of crude titanium powder produced by metallothermic reduction by acid leaching}

Table III

Experimental leaching conditions ${ }^{\star}$ for the removal of by-products

\begin{tabular}{|l|c|c|c|c|c|c|}
\hline Experiment ID & Solvent & Concn $(\mathbf{M})$ & Amount of crude product $(\mathbf{g})$ & Total volume of solution $(\mathbf{m l})$ & Stirring time $(\mathbf{h})$ & Stirring speed $(\mathbf{r} / \mathbf{m i n})$ \\
\hline 1 & $\mathrm{HCl}$ & 0.035 & 30 & 300 & & \\
2 & $\mathrm{HCl}$ & 1 & 30 & 300 & & \\
3 & Pure water & $\mathrm{N} / \mathrm{A}$ & 30 & 300 & & \\
\hline
\end{tabular}

*It should be noted that the experimental conditions were dynamic, as acid concentration fell throughout the process. The sample leached in water was allowed to reach the highest pH possible, a maximum $\mathrm{pH}$ of 2.5 with $0.035 \mathrm{M} \mathrm{HCl}$ sample and 1.5 with $1 \mathrm{M} \mathrm{HCl}$.
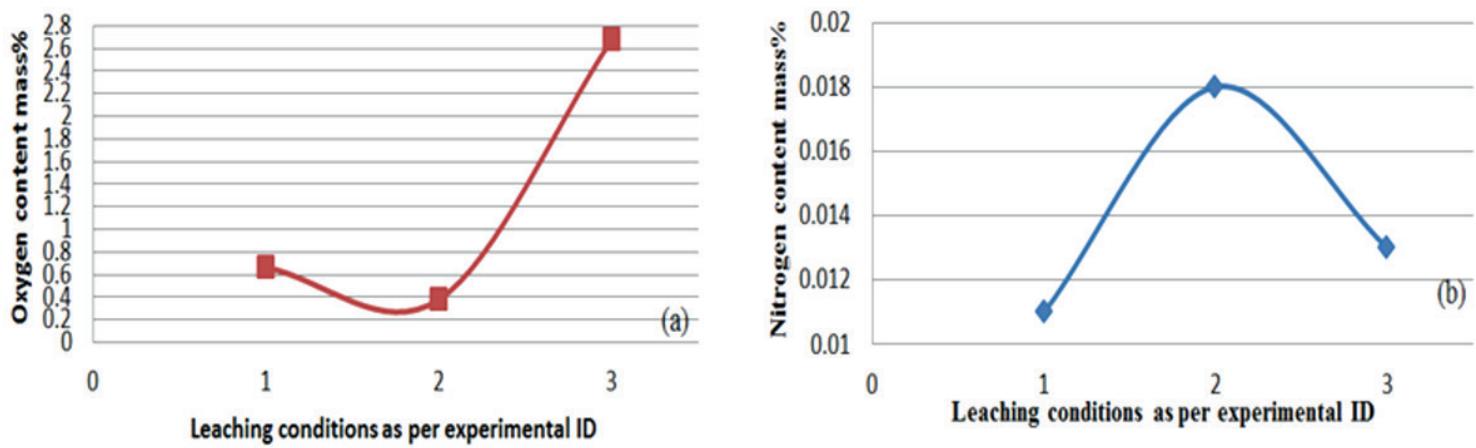

Figure 2-(a) Oxygen and (b) nitrogen content of titanium powders in the final product produced under the different experimental conditions
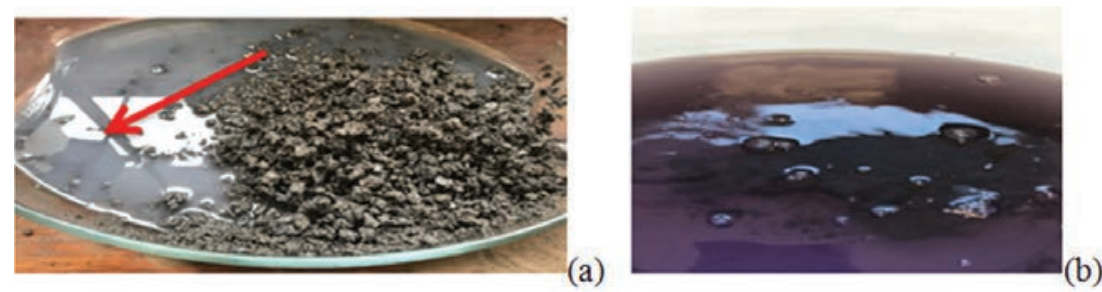

Figure 3-(a) Cloudy $\mathrm{TiO}_{2}$ in the leachate formed in sample leached with pure water and $0.035 \mathrm{M} \mathrm{HCl}$, (b) violet solution indicating Ti ${ }^{3+}$ (aq) in the samples leached in $1 \mathrm{M} \mathrm{HCl}$ solution

$$
\begin{aligned}
& 6 \mathrm{TiCl}_{2(\mathrm{~s})}+6 \mathrm{H}_{2} \mathrm{O}_{(\mathrm{l})} \rightarrow 4 \mathrm{TiCl}_{3(\mathrm{aq})}+2 \mathrm{Ti}(\mathrm{OH})_{3(\mathrm{~s})}+3 \mathrm{H}_{2(\mathrm{~g})} \text { ? } \\
& \text { Or } 2 \mathrm{TiCl}_{2(\mathrm{~s})}+12 \mathrm{H}_{2} \mathrm{O}_{(\mathrm{l})} \rightarrow 2\left[\mathrm{Ti}\left(\mathrm{H}_{2} \mathrm{O}\right)_{5}(\mathrm{OH})\right] \mathrm{Cl}_{2(\mathrm{~s})}+\mathrm{H}_{2(\mathrm{~g}) \text { ? }} \\
& \mathrm{TiCl}_{3(\mathrm{a} q \mathrm{~s})}+2 \mathrm{H}_{2} \mathrm{O}_{(\mathrm{l})} \rightarrow \mathrm{TiO}_{2(\mathrm{~s})}+3 \mathrm{HCl}_{(\mathrm{g} / \mathrm{aq}) \text { fumes in air }}+1 / 2 \mathrm{H}_{2(\mathrm{~g})}
\end{aligned}
$$

The hydrolysis products precipitated out as indicated in Figure $3 \mathrm{a}$, and concentrated on the surface and in the pores of the metal leading to contamination with oxygen.

The sample leached in $0.035 \mathrm{M} \mathrm{HCl}$ contained 0.51 mass \% oxygen, which is off-specification when compared to the CP Grade 4 oxygen content set as a benchmark for the CSIR Ti powder. However, compared to the water-leached powder, the product showed improvement. The unacceptable level of oxygen in the product, despite being leached in acid, is attributed to the excess reducing metal reacting with the acid solution, resulting in local depletion of the acid strength, with the result that some hydrolysis products formed when the hydrogen ion concentration fell below minimum, as indicated by the $\mathrm{pH}$ increase to 2.5 and as observed from the cloudy white $\mathrm{TiO}_{2}$ precipitate in Figure $3 \mathrm{a}$, even though it was expected that it would form much slower in an acidic medium. This phenomenon is a result of the low electronegativity of titanium (1.54) and the high polarizing power of $\mathrm{Ti}^{3+}$ and $\mathrm{Ti}^{2+}$ (Cotton and Wilkinson, 1988), which makes titanium subchlorides susceptible to hydrolysis.
The sample leached in $1 \mathrm{M} \mathrm{HCl}$ acid yielded the best result with an oxygen content of 0.38 mass $\%$, and by virtue of its oxygen specification adheres to CP Grade 4 . This is attributed to the hydrogen ion concentration not falling below $1 \mathrm{~g} / \mathrm{l}$ and the acid maintaining the $\mathrm{pH}$ below 2, thus retarding hydrolysis reactions. While most researchers have attested that the chemical compositions of aqueous titanium species in acid media are controversial, due to the difficulty associated with achieving thermodynamic equilibrium in these systems, it has been established that in non-oxidizing strong acids under reducing conditions a violet $\mathrm{Ti}^{3+}$ is formed and can remain in solution as the ion (Cotton and Wilkinson, 1988; Richens, 1997; Sole, 1999; Assi et al., 2017), as seen in Figure 3b. All the nitrogen assays were below specification, indicating that the passivation step during cooling was adequate to prevent the formation of, and contamination by, alkali/titanium nitrides.

\section{Effect of temperature on the leaching system}

The temperature of the bulk solution for all the leaching conditions was maintained below $50^{\circ} \mathrm{C}$ by leaching in a cooling water bath to retard the rate of precipitation and surface oxidation of the titanium metal by water (McKinley and Avondale, 1955), in order to preserve the quality of the product. It has been established that the rate at which titanium oxidizes in water increases with temperature in the order $0.025 \%$ when 


\section{Purification of crude titanium powder produced by metallothermic reduction by acid leaching}

the reaction mass is leached out at $30-40^{\circ} \mathrm{C}, 0.10 \%$ at $100^{\circ} \mathrm{C}$, $0.15 \%$ at $150^{\circ} \mathrm{C}$, and $0.2 \%$ at $200^{\circ} \mathrm{C}$ (Garmata et al., 1970). It was noted that for all the leaching conditions, the temperature increased sharply, particularly in the first 10 minutes of charging feed, as indicated in Figure 4, despite the high liquid to solid ratio and vigorous agitation. This is a consequence of the exothermic reaction between the leaching solution, excess reducing metal, and titanium subchlorides. However, after 20 minutes the temperature reached a plateau then decreased, indicating that equilibrium was reached and, most importantly, that the system favours preferential dissolution and neutralization of the byproducts, due to their low Ti coordination number compared to the reaction products, which explains their high reactivity towards water.

A cloudy milky solution was observed with the samples that were leached in pure water and in the $0.035 \mathrm{M} \mathrm{HCl}$ solution, as per Figure 3a, indicating that titanium dioxide precipitated out despite care being taken to ensure that the temperature was maintained below $50^{\circ} \mathrm{C}$, as advised. This might have been due to localized heating of the particles, as the measured temperature was that of the bulk solution, not the reaction contact point. However, with the solution leached at $1 \mathrm{M}$ (Figure $3 \mathrm{~b}$ ) it was observed that the colour did not change, proving the effectiveness of the acid solution in retarding the precipitation rate.

\section{Further analysis}

Further compositional observation of the $1 \mathrm{M}$ acid-leached product was done with a JEOL EDS system. The image showed a titanium metal phase in various grain sizes, as well as iron (points 001 and 002 in Figure 5). It was concluded that the source of iron contamination was the reactor material, which indicates that the sample was in contact with the surface of the

\section{Table IV \\ ICP assay results of the $1 \mathrm{M} \mathrm{HCl}$ leached sample (mass \%)}

\begin{tabular}{|l|c|c|}
\hline Iron & Carbon & Other \\
\hline 0.015 & 0.04 & 0.412 \\
\hline
\end{tabular}

reactor vessel. This deduction implies that the sample was either on the sides or bottom of the vessel, because care was taken to ensure that external iron contamination was minimized during leaching by using polypropylene equipment except for the stirrer. The iron-contaminated product may be removed by magnetic separation.

ICP-OES analysis was also performed on the same sample to quantify the metallic impurities in order to qualify the product. According to the results (Table IV), the product was on specification with regard to the iron, carbon, and other impurity requirements for CP Grade 4 (Carpenter Technology, 2004).

\section{Conclusion}

Hydrochloric acid was selected as a lixiviant specifically because it is a non-oxidizing acid that exhibits weak reducing properties, consists of common ions and thus does not introduce foreign species into the system, and its efficiency can be estimated by varying the concentration. It was established that under dynamic conditions where the hydrogen ion concentration is allowed to fall below the minimum, i.e. $\mathrm{pH}>2$, hydrolysis products of the subchlorides and alkali/alkali earth metals still form, and that at pH 1-1.5 the subchlorides oxidize but remain in the leachate in aqueous form. The procedure had the advantage that there was
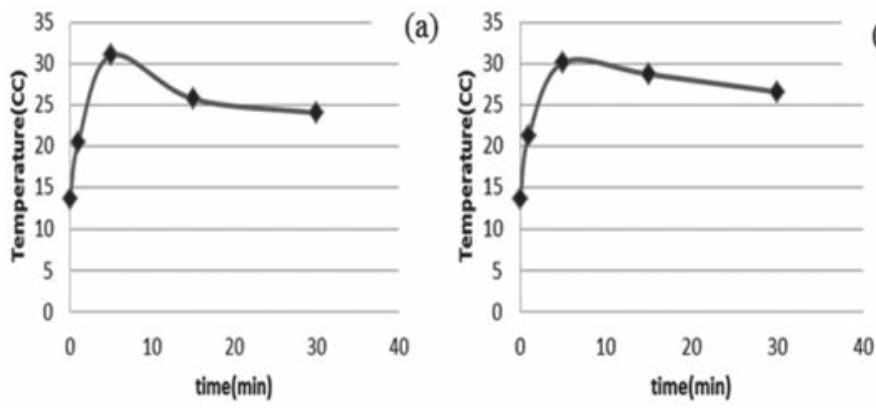

(b)

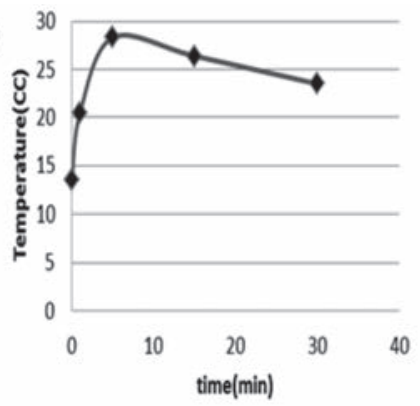

(c)

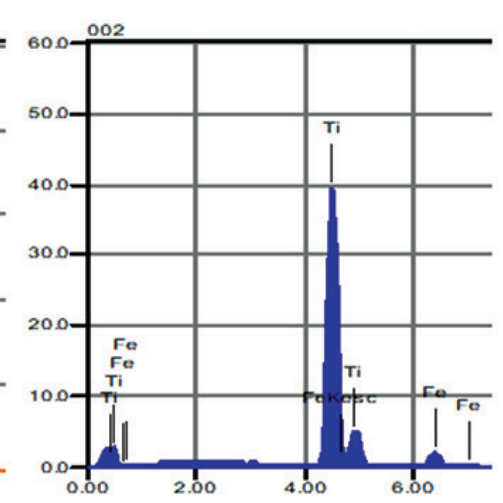

c)
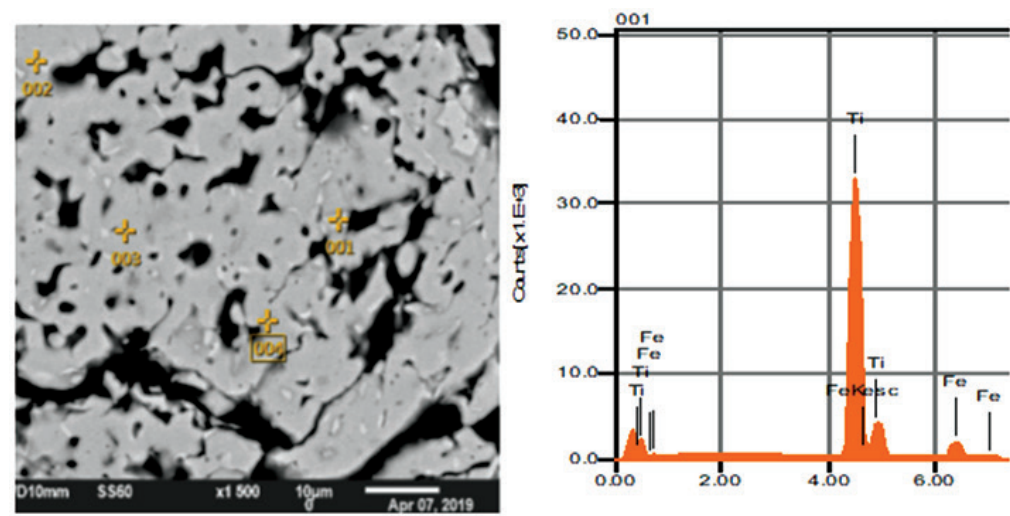

Figure 4-Temperature of the solution during the leaching process: (a) pure water, (b) $0.035 \mathrm{M} \mathrm{HCl}$, (c) $1 \mathrm{M} \mathrm{HCl}$

Figure 5-SEM image illustrating titanium metal particles after leaching 


\section{Purification of crude titanium powder produced by metallothermic reduction by acid leaching}

no need to top up or to dose any additional acid, which makes it easier to operate, and the total oxygen content after leaching was found to be below the $0.4 \%$ specified for CP Grade 4 titanium.

It was not necessary to leach at $\mathrm{pH} 7$ or in pure water, because according to the $\mathrm{Ti}-\mathrm{H}_{2} \mathrm{O}$ Pourbaix diagram (Assi et al., 2017), the domain of stability of anhydrous titanium (IV) oxide $\left(\mathrm{TiO}_{2}\right)$ extends across the whole of the $\mathrm{pH}$ range, indicating that it is the most stable species of titanium in ambient conditions (water and air). However, the test was done to demonstrate the need to leach in an acid medium and to also demonstrate that product integrity can be preserved in an acid medium.

This method has potential to be used as a purification step in the CSIR Ti process, especially considering that the final washing and rinsing was completed with process water that contained oxygen, and as a result a monolayer of oxide on the titanium particle may have formed, contributing to the total oxygen content of the samples (Hansen and Gerdemann, 1998). The leaching parameters were not kept constant in order to try to determine how flexible the system could be. There is a lot of scope to improve the process and quality of the product. Various fundamental studies to confirm whether the oxygen exists as a monolayer or an interstitial impurity are under way and will be the subject of a future report

\section{Acknowledgements}

The authors would like to thank the CSIR and the Department of Science and Innovation (DSI) for funding, the CSIR-TiCoc production team for advice, as well as the laboratory team for analysing the samples, without whom the results guiding the research would not have been possible.

\section{References}

Aleksandrovskil, S., Berdnikova, L.M., Lukashenko, G.S., Pinaev, E.N., and Snisar, G.P. 1982. Conversion of a sodium-thermic reaction mass into titanium powders. Soviet Powder Metallurgy and Metal Ceramics, vol. 21, no. 1. pp. 4-7.

Assi, H., Mouchaham, G., Steunou, N., Devic, T., and Serre, C. 2017. Titanium coordination compounds: From discrete metal complexes to metal-organic frameworks. Chemical Society Reviews, vol. 46, no. 11. pp. 3431-3452. doi:10.1039/c7cs00001d

Bolzoni, L., RuIz-Navas, E.M., and GoRdo, E. 2013. Processing of elemental titanium by powder metallurgy techniques. Materials Science Forum, vol. 765. pp. 383-387. doi:10.4028/www.scientific.net/MSF.765.383

Carpenter Technology. 2004. Product Datasheet CP Titanium Grade 4 Type Analysis Product Datasheet. Philadelphia, PA. pp. 1-10.

Coтton, F.A. and Wilkinson, G. 1988. Advanced Inorganic Chemistry. 6th edn. Wiley, New York. pp. 689-708. doi:10.1016/j.jaap.2011.11.019

Fang, Z.Z., Paramore, J.D., Pei, S., Chandran, K.S.R.; Zhang, Y.; Xia, Y., Cao, F., Koopman, M., and FreE, M. 2018. Powder metallurgy of titanium - Past, present, and future. International Materials Reviews, vol. 63, no. 7. pp. 407-459. doi:10.1080/09506608.2017.1366003

Froes, F.H. 2012. Titanium powder metallurgy: A review - Part 1. Advanced Materials and Processes, vol. 170, no. 9. pp. 16-22.

Froes, F.H. and Ashraf Imam, M. 2010. Cost affordable developments in titanium technology and applications. Key Engineering Materials, vol. 436. pp. 1-11. doi:10.4028/www.scientific.net/KEM.436.1.

Gambogi, J. and Gerdemann, S.J. 2001. Titanium metal: extraction to application. Review of Extraction, Processing, Properties and Applications of Reactive Metals. Brajendra, M. (ed.). Wiley, San Diego. pp. 175-210.

Garmata, V.A., Gulyanitskit, B.S., Kramnik, V.Y., and LipKes, Y.M.S.G. 1970. The Metallurgy of Titanium. Foreign Technology Division, Wright-Patterson Air Force Base, Dayton, OH. doi:10.7868/s0207401x1704015x
Goso, X. and Kale, A. 2011. Production of titanium metal powder by the HDH process. Journal of the Southern African Institute of Mining and Metallurgy, vol. 111, no. 3. pp. 203-210.

Hansen, D.A. and Gerdemann, S.J. 1998. Producing titanium powder by continuous vapor-phase reduction. JOM, vol. 50, no. 11. pp. 56-58. doi:10.1007/s11837998-0289-3

HocKADAY, S.A.C. and BISAKA, K. 2010. Experience and results from running of a 1 $\mathrm{kg}$ Ti scale Kroll reactor. Proceedings of the Advanced Metals Initiative: Light Metals Conference 2010. Southern African Institute of Mining and Metallurgy, Johannesburg. pp. 265-280.

KeLLY, J.T. 1963. Metal purification process.. US patent 3085874A.

Liang, L., Liu, D., Wan, H., Li, K., Deng, J., and Jiang, W. 2018. Removal of chloride impurities from titanium sponge by vacuum distillation. Vacuum, vol. 152. pp. 166-172. doi:10.1016/j.vacuum.2018.02.030

Low, R.J., QIAN, M., and Schaffer, G.B. 2012. Chloride impurities in titanium powder metallurgy - A review. Ti 2011 - Proceedings of the 12th World Conference on Titanium, 19-24 June 2011. Zhou, L. (ed.) Science Press, Beijing. pp. $1770-1774$.

McCracken, C.G., MotchenBacher, C., and Barbis, D. 2010. Review of titanium-powderproduction methods. International Journal of Powder Metallurgy, vol. 46, no. 5. pp. 19-27.

McKinley, T.D. 1955. Recovery of titanium metaL US patent US281653A. E. I. du Pont de Nemours and Company.

Nechaev, N.P. and Polezhaev, E.V. 2016. Effect of physicochemical treatment on titanium porous powder quality. Metallurgist, vol. 60, no. (3-4). pp. 339-341. doi:10.1007/s11015-016-0296-5.

Oosthuizen, S.J. 2011. Titanium: the innovators' metal - Historical case studies tracing titanium process and product innovation. Journal of the Southern African Institute of Mining and Metallurgy, vol. 111, no. 11. pp. 781-786.

Oosthuizen, S.J. and Swanepoel, J.J. 2018. Development status of the CSIR-Ti Process, IOP Conference Series: Materials Science and Engineering, vol. 430, no. 1. p. 012008. doi:10.1088/1757-899X/430/1/012008

Peters, W., Chen, W., Yаmamoto, Y., and Williams, J. 2012. Current status of Ti PM: Progress, opportunities and challenges. Key Engineering Materials, vol. 520, August 2012. pp. 1-7. doi: 10.4028/www.scientific.net/KEM.520.1

Poulsen, E.R. and Hall, J.A. 1983. Extractive metallurgy of titanium: A review of the state of the art and evolving production techniques. JOM, vol. 35 , no. 6 . pp. 60-65. doi:10.1007/BF03338304

Richens, D. 1997. The Chemistry of Aqua Ions. Ellis Horwood, Chichester.

SoLE, K.C. 1999. Recovery of titanium from the leach liquors of titaniferous magnetites by solvent extraction: Part 1 . Review of the literature and aqueous thermodynamics. Hydrometallurgy, vol. 51, no. 2. pp. 239-253.

Sun, P., FAnG, Z.Z., ZHAng, Y., and XIA, Y. 2017. Review of the methods for production of spherical Ti and Ti alloy powder, JOM, vol. 69, no. 10. pp. 1853-1860. doi:10.1007/s11837-017-2513-5

VAN VUUREN, D.S. 2009. A critical evaluation of processes to produce primary titanium. Journal of the Southern African Institute of Mining and Metallurgy, vol. 109 , no. 8. pp. 455-461.

VAn Vuuren, D. S. and Oosthuizen, S.J. 2012. Titanium powder production process. US patent US20130000449A1. CSIR, South Africa.

Van Vuuren, D.S., Oosthuizen, S.J., and Heydenrych, M.D. 2011. Titanium production via metallothermic reduction of $\mathrm{TiCl}_{4}$ in molten salt: Problems and products. Journal of the Southern African Institute of Mining and Metallurgy, vol. 111, no. 3. pp. 141-148.

WaRTMAn, F.S. 1949. Production of titanium powder at Boulder City, Nevada. US Department of the Interior, Bureau of Mines.

YAN, M., TANG, H.P., and QIAN, M. 2015. Scavenging of oxygen and chlorine from powder metallurgy (PM) titanium and titanium alloys. Titanium Powder Metallurgy: Science, Technology and Applications.: Quian, M. and Froes, F.H. (eds.). Elsevier. pp. 253-276. doi:10.1016/B978-0-12-800054-0.00015-0 